\title{
Livelihood Resilient Strategies through Beekeeping in Chitanga Village, Mwenezi District, Zimbabwe
}

\author{
Bernard Chazovachii ${ }^{1}$, Maxwell Chuma ${ }^{2}$, Alimos Mushuku ${ }^{1}$, Leonard Chirenje ${ }^{3}$, \\ Leonard Chitongo ${ }^{1} \&$ Raphel Mudyariwa ${ }^{1}$ \\ ${ }^{1}$ Department of Rural and Urban Development, Great Zimbabwe University, Zimbabwe \\ ${ }^{2}$ Department of Sociology, Great Zimbabwe University, Zimbabwe \\ ${ }^{3}$ Department of Social Ecology, Great Zimbabwe University, Zimbabwe \\ Correspondence: Bernard Chazovachii, Department of Rural and Urban Development, Great Zimbabwe \\ University, Zimbabwe. E-mail: bchazovachii@gmail.com
}

Received: September 18, 2012 Accepted: November 1, 2012 Online Published: November 10, 2012

doi:10.5539/sar.v2n1p124

URL: http://dx.doi.org/10.5539/sar.v2n1p124

\begin{abstract}
The study sought to establish the contribution of beekeeping in rural livelihoods sustainability. Chitanga village had experienced low agricultural productivity due to poor and infertile soils and this has led to food insecurity which had driven them into beekeeping. This opportunity has been driven by the existence of tall trees and wild plants that develop flowers in the village which attracted bees. However, the utility of beekeeping enterprise as a livelihood activity has not been fully realised. This study was carried out in the context of a sustainable rural livelihoods framework. This framework states that at any given time, every community or society falls under a vulnerability context as a result of both natural and human made disasters. In light of the vulnerability, a community mobilises the various forms of its assets at its disposal to earn a living. Applying this framework, the study analysed the strategies the community employed to enhance its livelihoods through the sharing of benefits. The research used questionnaires, structured interviews and observations as sources of gathering data. The study established the benefits which accrued from beekeeping that included honey as food, income in the form of cash, medicines, scenery creation for tourism and income generating projects through making of hives, growing of flowers and citrus fruits which attract bees. A backward and forward linkage of enterprises emerged. Employment creation and increasing in the number of livelihood activities in the area has been witnessed due to beekeeping. This culminated in diversification of livelihood options leading to rural transformation through utilization of local available resources. The study recommends that the sustainability of beekeeping enterprise should be reinforced by backward and forward linkages. The government partnered by NGOs should take the lead and compliment the efforts of beekeepers by providing clear policy and planning.
\end{abstract}

Keywords: beekeeping, resilient rural livelihoods, sustainability

\section{Introduction}

Rural livelihoods are predicated upon rural people's accessibility to natural resources such as land, water and biotic resources. The improvement of people's lives and meeting their needs has been the most crucial and priority task by most developing countries all over the world. Sustainable management of natural resources, enhancing livelihoods and food security among rural communities at regional level and global level has been the business of every stakeholder. (Veronica, 2011). The United Nations (2011) encouraged communities to conserve forests after realising that forest goods and services remain very critical to the poor and marginalized communities since they contribute to the reduction of poverty in rural areas. The beneficial and sustainable use of forests to uplift rural livelihoods has added calls for governments to craft and implement appropriate policies to conserve forests. In most African countries, agriculture has remained the backbone of the economy, although many other livelihoods activities are being copied and adopted due to inadequate and inconsistent rains, poor infertile soils and geographic areas that are prone to drought and hunger. This has resulted in many countries focusing on non agricultural activities.

Apiculture is a positive programme that not only contributes to the uplifting of the rural communities but also protecting the trees thereby enhancing the protection of our planet earth through conservation of the natural 
resources. It has a long tradition in Africa dating back several centuries when beehives were first used for producing honey in ancient Egypt. It promotes economic self reliance and has become a life sustaining source of income and livelihoods particularly for the poor. Beekeeping is an ecologically and traditionally appropriate form of income generation for communities in some of the poorest areas in African countries such as Mozambique, Malawi, Kenya and Zimbabwe just to mention a few. The realisation of the value of protecting and conserving forests through beekeeping has led Environmental Africa, an NGO to initiate and implement a number of beekeeping projects in various districts in Zimbabwe (Beekeepers Association in Zimbabwe (BKAZ), 2002).

In Zimbabwe, agriculture currently accounts for about $20 \%$ of the country's GDP (Scoones, 2010). The sector has however been characterised by massive decline in productivity over the past decade, mainly due to the country's disastrous and underperforming land reform program. Other factors that have negatively affected the agricultural potential in the country include droughts induced by climate change, floods and unstable political environment that have discouraged international support and investment in the sector. Subsistence farming, livestock management, wage employment and self employment using the locally available resources has become popular in Zimbabwe as a source of income generation as well as increasing food production and availability (Scoones, 2010). With soaring summer temperatures and unreliable rainfall in the district making it difficult to harvest anything from the field, many people have been forced to think outside the box. This has led to livelihood diversification through involvement in on-farm, off-farm and non-farm activities and has managed to transform people's lives (Scoones, 2010).

To improve the quality of life of the local vulnerable and marginalised people, Environmental Africa supported more equitable and sustainable management of natural resources especially in the light of climate change and resources scarcity. Environmental Africa is a private voluntary organisation that was set in 1990 to generate action towards the protection and management of natural resources for sustainable development. The NGO initiated and implemented a plethora of beekeeping projects in various districts within Zimbabwe and one of the communities involved in this program are the residents of Chitanga village, Mwenezi district. Against this background, this paper seeks to establish the contribution of beekeeping in rural livelihood sustainability particularly in Zimbabwe.

\subsection{Statement of the Problem}

There has been low agricultural productivity in most dry areas of Mwenezi district which lies in regions 4 and 5 due to low mean annual rainfall patterns. This has resulted into severe problems such as food shortages and lack of capacity to access basic needs. It left the people of Chitanga with no option expect to take the existence of tall trees and wild plants as an opportunity to concentrate on aerial agricultural activities, that is, beekeeping. Due to recurrent unreliable rainfall pattern, the community has been forced to venture into beekeeping since they have not been realising low yields from crop farming. However, since its inception by Environment Africa as a livelihood strategy, its utility has not been fully realized. Therefore, the paper seeks to examine the contribution beekeeping to rural livelihoods sustainability. The study was significant since it would not only benefit depressed rural people's livelihoods diversity but also preserve and conserve the natural asset in existence.

\subsection{Conceptual Framework}

Beekeeping tends to be perceived by the general populace as 'a hobby', or as 'a sideline activity'. These descriptions may often be true, but as a resilient livelihood, it keeps people out of poverty as it allows a wide range of options. In this case, apiculture and related trades can be sources of valuable strength to countless numbers of rural people's livelihoods. The contribution of beekeeping to rural household livelihoods cannot be underestimated particularly to those communities where access to income is limited. However, Apiculture tends to be underplayed in both policy and planning. One reason may be the focus of rural development, wherein crop production and livestock rearing are perceived to be dominant activities in rural areas. This perspective can render invisible the part beekeeping plays in social life, culture, and local economies.

\subsection{The Origins and Evolution of Beekeeping}

Beekeeping is an aerial agricultural activity that does not occupy cultivated land, requires less investment and benefits can be obtained quickly, besides it being a non polluting intensive agriculture (Conarad, 2007). This means that there is sustainability and availability of beekeeping requirements as it is based on locally available resources which utilises both the traditional and modern hives. Apiculture or beekeeping has to do with the preservation of honey bees' colonies in hives by humans. The collection of honey products and those of the hive such as bees wax, propalis, pollen and royal jelly is central to beekeeping. This type of farming is also crucial for the pollination of crops as well as producing bees for sell to other beekeepers, (Kerealem, Ejigu, \& Preston, 
2009). There are various species of wild bees and some of the species are solitary such as the 'mason bees' and many others rear their young in burrows and small colonies such as the bumble bees. Wildman (2009) noted that all these species are capable for inter-breeding and hybridizing and they later spread quickly around the world. Breeding companies hybridize varieties to produce desirable quality which are resistant to disease and parasite, good honey production, swarming behaviour reduction, prolific breeding and mild disposition. In Africa, Asia, Australia and South America, wild honey harvesting is still practised, and it is done by subduing, the bees with smoke, though rudimentary (Matti, 2010). However, humans began to domesticate wild bees in artificial hives using hallow logs, wooden boxes, pottery vessels and woven straw baskets. Conarad (2007) reiterated the invention of movable comb hives. Traditionally the collection of honey involved the destruction of the whole colony when the honey has been harvested. During the harvesting of honey, smoke was used to suppress the bees; resulting in honey combs toned out destroying the whole life cycle of the bee and the honey they contained. Liquid honey from the destroyed brood nets was strained through a destructive and unhygienic sieve or basket, (Matti, 2010).

In the $19^{\text {th }}$ century, the evolution of beekeeping to present promoted eco-environmental beekeeping. New methods of harvesting honey are done through perfection of the movable comb hives, (Wildman, 2009). This brought about an explosion of innovations that perfected the design and production of bee hives systems of management. Beekeeping requires the equipment, strength of colonies management techniques, weather or good growing conditions for plants that produces nectar, (Conrad, 2007). In order to harvest a good honey crop, there is need for strong hives of healthy bees with good queens, good location, thus the area must have a good history of good honey production and located a distance from vehicles as well as human dwellings. Beekeepers must treat the bees with various miticides or other treatments that assist the bees to combat the mortality that occurs when bees are not treated and it is normally done after the removal of honey supers as soon as the bees are examined in the spring (Flottum, 2007).

\subsection{Creating a Livelihood from Beekeeping}

According to Chambers (1983), capabilities, assets and activities constitute livelihoods required for one to earn a living. Human being can enjoy a sustainable life if they can cope with and recover from stress and shocks. Rural people's livelihood depends upon access to different types of assets. In order to make it possible to think about people's differing livelihoods, and to allow analysis, all assets may be allocated into one of five fundamental categories: human, physical, financial, social and natural (DFID, 2002). An appreciation of this requires one to think about his or her livelihood and all the diverse assets needed that include one's skills; physical resources and social integration. No single category of capital asset - for example finance - is on its own a sufficient basis for creating a livelihood. Beekeeping reinforces human life through a variety of assets. According to Lemessa (2007), successful beekeeping can be achieved by drawing upon all of the five categories of capital assets.

Livelihoods rely on natural capital in the case of beekeeping, these are bees, flowering plants and water. Bees feed on the nectar and pollen from flowers, the nectar is eventually converted into honey. Gums and resins are collected from plants, which again act as habitat for nesting places. Bees are a natural asset accessible in the wild. They collect honey ingrediences where they can, hence wild; wastelands and even land-mined areas all have value for beekeeping. Beekeeping is therefore, possible in arid areas as a livelihood resilient strategy. It provides an excellent bonus crop in addition to, but not a substitute to other crops. Bees are the only livestock with no competition with other animals with the capacity to harvest nectar and pollen (Lamessa, 2007). The most important aspect in beekeeping is assurance in the continuation of natural capital by the pollination of plants, as bees visit flowers, they are not only collecting food for today, but by their pollinator activities are ensuring new generations of food plants. As Veronica (2011) argues, beekeeping fits well alongside many other livelihood activities and the natural resources used by them, for example, forestry, agriculture and conservation activities. Although impossible to quantify, pollination is the most economically significant value of beekeeping. Flowering plants and their associated bees are interdependent. It is clear that beekeeping helps to sustain the natural capital. Whilst it has been in the past, a regular part of village agriculture worldwide, there is need to ensure that it is retained as farming practices change.

Traditionally, many societies have good skills relating to bees, honey and in making other products. The Ethiopian case study revealed that women utilize products from beekeeping to make secondary products. Their industry of Tej (honey wine), is administered by women in other African countries (Belie, 2009). Women often brew and sell honey beer. This has brought human capital within the society and best project recognize existing skills and build on them for ensuring sustainability and sustainable development, (Mathewos, Algaresh, \& Gizaw, 2004). Physical capital include build up structures like roads, building production equipment that enable people to earn a living out of them. People have these equipments like hives for beekeeping .But failure to have other 
forms of capital to support the physical asset (beekeeping) would derail the success of the project. For the beekeeping project to succeed, materials used must be locally manufactured. This could help also local people in their livelihood. The enterprise can stimulate various sectors within a society like village traders, carpenters, trailors, container-makers and sellers. The equipment needed for beekeeping like the humble plastic is one of the most useful items. It must be noted that social networks, market integration are key for the development of beekeeping .The network allows beekeepers to ensure protection of their bees, processing and marketing support. Access to a network at higher levels assists the enterprise to establish contact with national and international networks and find out market, training sources and raising awareness of the trade and their opportunities.

Availability of financial resources is essentially important for the development of beekeeping enterprise. This would enable packaging and making of products successful. Credit facilities are necessary for beekeeping associations running collection centres, buying products from producers and selling in bulk. However, significant financial assets are not essential for beekeeping at subsistence level, although having access to financial resources may be important for a family. Mathewos et al. (2004) noted that a good beekeeping project will work to ensure that all available capital assets are taken into consideration without dependence on any that are not. For example, too many projects have depended on the importation of the beeswax foundation used in frame hives, making this impossible for beekeepers without financial assets. According to the Beekeepers Association of Zimbabwe (BKAZ) (2002), beekeeping favours or is suitable in dense forest areas with tall trees and crops which produces nectar. These characteristics are common in Chitanga village which means that beekeeping can be regarded as a co-option. The fact that some activities being prohibited by the government and its quasi-agencies because they are regarded as unfriendly to the environment, beekeeping can come in since it is environmentally friendly. To add, it also requires less investment as well as generates quick incomes. Therefore, beekeeping can assist farmers to alleviate poverty through accessing basic needs and goods. However, the locals should appreciate the benefits that can be accrued from it since it constitutes their lives.

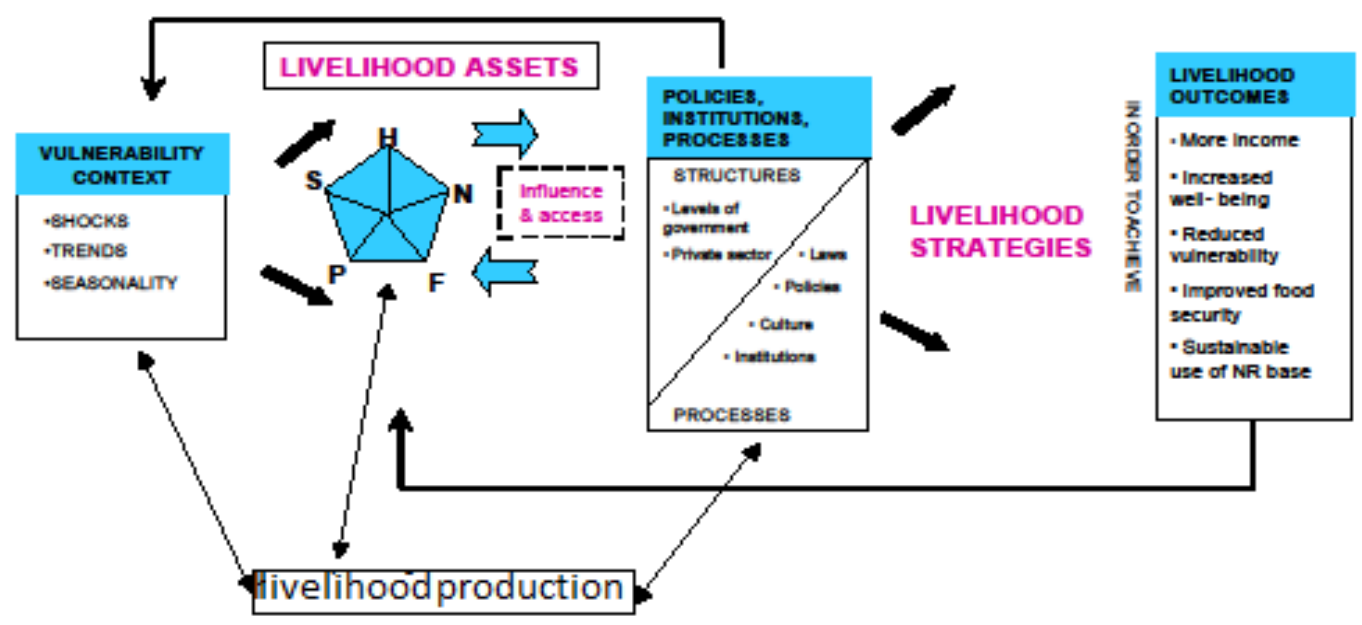

Figure 1. Sustainable livelihoods framework (Source: Ellis, 2000.)

Serrat (2008) noted that there is need for the utilisation of the sustainable livelihood management through the adoption of the sustainable framework implying that the sustainable livelihood framework is an important tool which influences a deeper analysis of how communities earn their living. It works in conjunction with other approaches such as integrated rural development in a holistic manner, (Serrat, 2008). The influence of the five forms of capital which are embedded in the mediating processes is influenced by the institutional framework. Scoones (2010) noted that to have a deep introspection on how livelihoods develop the nature and nurture of institutional and organisational structures should be analysed. There are three insights into poverty which underpin this new approach, (Krantz, 2001). First economic growth does not necessarily lead to poverty reduction. Second, there is the realisation that poverty is difficult to measure. It is not just about low income, but also a combination of other factors that include poor health, illiteracy and feelings. There is now a greater realisation that the people who can explain the nature and magnitude of their severity. Hence they should take a greater lead into the designing of policies and projects. According to Serrat (2008) livelihood outcomes cannot be attained without public participation.Vulnerabilty context cannot be averted by structures and processes alone 
but through an understanding of people's context and how assets are used.

The beekeeping enterprises have been seen to improve crop yield and environmental conservation (Kerealen et al., 2009). The enterprises have also brought interest to communal farmers and this has led to increased participation among the rural communities. Mathewos et al. (2004) noted that Africa has a conducive natural environment that can be used as honey bee forages for the production of honey. Challenges in beekeeping are found in the production systems and vary with agro-ecological regions, cultural practices, socio-economic conditions, and climate and bee behaviour. Other factors are agro-chemicals, shortage of morden hives, market problems and disease prevalence (Kerealen et al., 2009). Furthermore, although the sustainable livelihoods framework assists in the identification of the capitals that are passed by humans and assist them with those capitals that they lack as well as helps in alleviating poverty. The approach however, only deals with the issue of how to assist and not identifying the poor people and also it has a basic idea of how to start and ending of projects. Furthermore, currently, a properly designed apiculture sector development policy in many countries which assist the farmers and the governments are also offering modern bee hives at subsidized prices, thus it built the capacity of the farmer, (Kerealem et al., 2009).

\section{Research Methodology}

The research used both qualitative and quantitative methods to capture and analyze data. The reason behind using both methods is to strengthen the data analysis and to eliminate data gaps. The research chose forty (40) respondents from the population. This allowed the gathering in-depth information of how the villagers viewed the adoption of beekeeping in their area. The research used the random sampling technique, whereby the number of the households were written down then picked those numbers randomly for instances $1,4,12,35 \ldots$ These randomly picked households became the respondents. The researcher interviewed the households directly on the benefits accrued in beekeeping and factors that led to the adoption of beekeeping as an option. Structured interviews provide quick access to prior history of the situation and help to identify other sources of evidence on the issue. There was enough time with the respondents that enabled the interviewer to directly focus on the topic and to easily follow the line of inquiry stated by the research question insightfully, providing answers to what interviewees perceive to be the cause of phenomena in question (Zandeni, 1988). Secondary data sources were also used to incorporating the livelihood framework which analysed the strategy the community employed to enhance its livelihoods through the sharing of benefits. The data was presented in graphs, pie charts and tables for quantitative results and content analysis for in-depth interviews and observations.

\section{Results and Discussions}

Age-Sex Distribution of Respondents

Table 1. Age-Sex Distribution

\begin{tabular}{ccccc}
\hline Age & Females & Males & Total & Percentage (\%) \\
\hline $0-19$ & & & & \\
$20-40$ & 9 & 23 & 32 & 80 \\
$41-60+$ & 3 & 5 & 8 & 20 \\
\hline
\end{tabular}

Source: Field Survey, 2011.

The majority of the respondents ( $80 \%$ ) were the economically active groups in the age group 20-40 years, while those within $40-60+$ age groups were of $20 \%$. The males constituted a greater percentage in beekeeping than females as shown in Table 1 above.

\subsection{Educational Qualifications of Respondents}

The findings revealed that the majority managed to reach secondary school level, with $(10 \%)$ having attended tertiary education and $(20 \%)$ did not go to school at all. Beekeeping is revealed to be a source of employment for the learned people. Sustainability in their activities is witnessed as they adopt new skills and ideologies easily from the project initiators because of their capability.

The Table 2 shows that the average incomes of the people of Chitanga village are poor and this has pushed them to engage in beekeeping as a livelihood option to generate income. Findings revealed that due to rampant unemployment in today's urban areas, most educated people in the village who are economically active and able 
bodied have taken beekeeping as an employment opportunity rather than increasing congestion in towns and cities. Therefore beekeeping has come as a refuge for rural dwellers.

Table 2. Distribution of respondents by income

\begin{tabular}{cc}
\hline Income in US\$ per month & Percentage (\%) \\
\hline $0-10$ & 20 \\
$11-40$ & 55 \\
$41-80$ & 15 \\
$81-100$ & 6 \\
$101+$ & 4 \\
\hline
\end{tabular}

Source: Field Survey, 2011.

\subsection{Beekeeping Techniques Employed in the Area}

Data gathered from the respondents revealed that both traditional and modern technologies are being used by the villagers. The villagers make use of both local resources and ideas and the modern techniques in the project of beekeeping, with the modern ideologies and equipment being the dominant as compared to traditional. Traditional techniques include hives made out of trees barks, hallow logs and those which were sited beneath rocks hallows or cracks, while fixed comb hives, movable hives and top bar hives made from wood with one transparent side in the form of a glass that allows the beekeepers to witness or view clearly all the activities taking place inside the hives were the types of modern hives. Savannah Delight another NGO operating in the Chitanga area has played a pivotal role by assisting the villagers with modern hives, which are proving to be dominant in the area as compared to the traditional ones since they provide the needed security for the bees. The supplied hives are wide with greater carrying capacity which enables the honey making process freely and increase the quantity of the honey; and also they allow the beekeepers to monitor and clean the hives easily in a sustainable manner. The wood was treated using oil so as to prevent it from potentially threatening insects such as termites and ants to enter in and also from destroying the hive. Some were hanged on trees and tightened by a wire which was covered or spread with Vaseline, greases, wax and dung so as to stop the insects from going inside as they reduce the pace or smoothly process of honey making. There were only small holes which could only allow the bees in and out and thereby allowing enough heat inside which is required by the bees during their honey making process. Inside the hives, wax from other old hives could be witnessed and the brown sugar syrup which performed the role of nectar could be noticed, thus a supplementary food to the bees. This syrup was also used to attract the bees especially into the new hives. Besides the syrup, other farmers used a bee insect spray to attract the bees. Improved breeds of bees acquired from other farmers were usually brought in a cooler box or in a solid form (sealed) and could start to be active after few hours.

\subsection{Beekeeping and Livelihoods Enhancement in Chitanga Village}

Most villagers appreciated the role of beekeeping in improving their living standards and it has been seen as a saviour in the reduction of poverty by providing the much needed food and money whilst performing other chores. Beekeeping has been reinforced through backward and forward linkages which means that the villager's activities and beekeeping influence each other through the improvement in human, social, natural, physical and financial capitals. It has managed to generate income for the villagers from the sales of raw honey, bee hives and through tourism. According to the villagers, a single hive harvest produces about twenty (20) litres of raw honey, which they sell in 350 millimetre $(\mathrm{ml})$ bottles at between US $\$ 3.50$ to US $\$ 5.00$. Their annual income ranges from US\$180.00 to US\$380.00. This is better compared to the income of one tonne of maize (about US\$285.00), after applying chemicals, seeds and labour which are regarded as very expensive by the villagers. The average income realised from beekeeping is relatively substantial compared to the income from their previous business they engaged into. See Table 2. Some villagers are also earning from selling bee hives to the NGO, Savannah Delights which later assist other farmers by distributing them for free while some people are involved in the growing of flowers and citrus trees which attract bees thereby influencing the progress of beekeeping. One of the beneficiaries from beekeeping who has been involved in the project for the past 15 years, testified how beekeeping has contributed much in his life;

\section{"I come from a humble and poor background and for 20 years,}




\section{I slept in a traditional granary until I managed to build a 4}

bed roomed house from the proceeds from honey", he said

Observation revealed that patience, persistence and determination have contributed to the success of the villagers because beekeeping requires consistent monitoring and management and it is time consuming.

Furthermore some villagers testimonied that they have regular source of income from beekeeping and now are able to plan and buy inputs for other farming activities and paying school fees for their children at the same time. This meant that they now have access to financial capital which is vital for the villagers' lives thus essential for the further development of beekeeping enterprises through successful markets.

With the Savannah Delights monitoring every progress in the project, it has resulted in great improvement in the area thus through infrastructure development (physical capital). Almost every household in the village owns one or more hives due to the creation of market opportunity facilitated by Savannah Delights which provides apprenticeship for the villagers and later buy their produce, thus human capital leading to the development of the village. Most of the honey is sold to the pharmaceutical companies, supermarkets such as Masvingo Spar and TM and other industries. The way the hives are sited in trees and their numbers has led to the village benefiting through recreational areas established. Thus rural tourism emerged eco-friendly production of honey, as people are keen to see the bees, production of honey and the raw honey itself naturally, because people are only aware of the honey products in shops. Revenue is generated from the visitors who are charged a fee the villagers and some also buy the honey on their way back.

The village has also managed to obtain food from beekeeping besides the benefits of income or financial capital. Besides being consumed directly, honey is used by the villagers as relish, thus consuming it with sadza (maize meal). This is a nutritional and healthy meal for their bodies therefore reducing the level of malnutrition in the village especially for children. The same honey is also used as a spread on bread which has substituted the need of peanut butter, margarine, sausages or bacon which are relatively expensive to access by the villagers. Therefore honey is nutritious and recommended by the health practitioners, thus improving the Chitanga people's health and diet.

Moreover honey is also used for herbal purposes by the Chitanga village and recommended for tuberculosis (TB), HIV and asthmatic patients. In the African context or from traditional perspective, it is believed that trees are herbal in nature, therefore bees make use of nectar collected from different trees (both indigenous and exotic), it meant that honey is a reliable and strong medicine which is equally good as conventional medicines. This meant that the villagers are making use of honey as a substitute to herbal treatment as they cannot afford to buy conventional medicines which are expensive in Zimbabwe.

As Lamessa (2007) asserted, employment opportunity has also been created to the villagers through beekeeping. The Chitanga people are learned people since they had managed to reach secondary school level (see Figure 2). The most economically active groups are engaging in beekeeping rather than migrating to towns or to other countries such as South Africa seeking employment which is hardly available. The engagement of the villagers in beekeeping means empowerment and self reliance in the enterprise to such an extent that if Savannah Delights decided to withdraw from the project it will still continue to be done. It has also managed to increase the number of livelihoods activities in Chitanga area thereby increasing the chances and opportunities of employment. Bi-products from beekeeping are also utilized by the villagers as animal supplementary feeds. Livestock such as pigs and cattle enjoy the residues from honey which also improve their reproductive performance. The villagers attributed the increased numbers of their young ones to the effects of honey residue as a supplementing feed. Beeswax is also a valuable product from beekeeping. The beekeepers and other people in the community create further assets by using honey and beeswax in the manufacturing of lighting candles, beauty creams and in brewing beer for the community.

Moreover, because of apiculture, the least visible livelihood outcome was the pollination, this is an outcome impossible to quantify. Various scholars have argued that beekeeping tends to enhance agricultural productivity and hence food production through increased pollination and complementary to biodiversity conservation. Thus regenerating natural capital according to Lamessa (2007) and ensuring sustainable production of both food plants and bees. The research observed that in the village, beekeeping is integrated with crop husbandry; increasing crop yield and quality and boosting financial asset base. Therefore cross pollination by bees in their search for nectar improves the growth of the ecosystem in the village. The engaging of the Chitanga people in the project and the assistance provided by Savannah Delights with modern techniques and ideologies managed to increase the sustainability and conservation of the natural resources. For example, the substitution of traditional way of using fire in harvesting the honey as it destroy the bees and surrounding natural resources with modern ideas 
which preserve wildlife.

Despite numerous spin offs from beekeeping, the research noted that the villagers are doing well and already yielded results through the support of private companies such as Savannah Delights, pharmacist and supermarkets such as Masvingo Spar and TM in providing markets. Savannah Delights provides apprenticeship for the villagers and later buy their produces. This integrated approach has strengthened the sustainability of the project. In addition to financial value, honey and beeswax have many cultural values and is used during ceremonies for birth, marriages, funerals, Christmas and other religious celebrations in the village. Beekeepers are generally respected for their craft. All of these aspects are livelihood outcomes from the activity of beekeeping. While some may be difficult or impossible to quantify, they can be attributed to strengthen people's livelihoods and therefore should be acknowledged by a beekeeping intervention.

\section{Conclusions}

Most people in Chitanga have found refugee in beekeeping as they are now able to meet the basic requirements of life. This is because of the benefits accruing to the villagers such as food, bi-products, medicinal, pollination which promotes sustainability in biodiversity, income generation through the sales of honey, bee hives and tourism as an industry, as well as employment creation. The most economically active members in the village are engaging in beekeeping than other groups. This meant that rather than overcrowding in towns and cities looking for employment which is difficult to come by due to current economic challenges. The villagers have adopted beekeeping as an opportunity to reverse the traditional rural to urban migration. The fact that learned people of Chitanga village are also involved in beekeeping, as shown in Figure 2, reveals that there is sustainability in beekeeping. Initiating rigorous training programs for the locals by development agencies focusing on beekeeping and honey production incorporating all age groups would sustainably anchor the Chitanga extension services on equipments to use and beehive construction. All this should be done with the support of the relevant government departments, particularly the Ministry of Environment and Tourism in the maintenance of natural scenery available. Integrating the Ministry of Rural Resource, Ministry of Environment and Rural Development and Resettlement Ministry would further strengthen rural sustainability through beekeeping enterprises. For the success of the enterprise, backward and forward linkages should be sustained by incentivising retailers in promoting local beekeepers for sustainable rural development.

\section{References}

Belie, T. (2009). Honeybee Production and Marketing Systems, Constraints and Opportunities in Burie District of Amhara Region, Ethiopia Thesis Submitted to the Department of Animal Science and Technology, School of Graduate Studies Bahir Dar University.

Chambers, R. (1983). Rural Development, Putting the Last First. London: Longman group.

Conarad, R. (2007). Natural Beekeeping: Organic Approaches to Modern Api-Culture. London: Chelsea Green.

Department for International Development (DFID). (2002). Sustainable Livelihoods and Poverty Elimination.V346 94Victoria Street, S-Montaga.

Ellis, F. (2000). Rural Livelihoods and Poverty Reduction Policies: London: Routledge.

Flottum, K. (2007). The Backyard Beekeepers Revised Updated: An Absolute Beginners' Guide to Keeping Bees in your Yard and Garden. Washington: Paperback, Chelsea.

Hussein, H. (2000). Beekeeping in Africa-North East, North West and Western African countries. Egypt, Assuit University.

Kerealem, E, Ejigu, T. G., \& Preston, T. R. (2009). Constraints and Prospects for Api- Culture Research and Development in Amhara region. Ethiopian, ARC.

Krantz, L. (2001). An Introduction to the Sustainable Livelihood Approach to Poverty Reduction, Sweden, IDA

Lemessa, D. (2007). Beekeeping: A Livelihood Strategy in Pastoral and Agro-pastoral Dry Land Areas of Southern Oromia (Libian District) and Somali Regional States, Filtu and Dolle.

Mathewos, B., Algaresh, T., \& Gizaw, K. (2004). Farm Animal Biodiversity in Ethiopia status and Prospects. Ethiopian. SAPES.

Matti, M. (2010). Beekeeping in Africa. Denmark, Danish Beekeepers Association.

Melkote, S. R. (1991). Communication for Development in the Third Word. New Dehli, Sage Publications.

Scoones, I. (2010). African Issues. Zimbabwe Land Reform. Harare, Weaver Press. 
Serrat, O. (2008). The Sustainable Livelihoods Approach. Manila, Philippines. Asian Development Bank.

Taylor, P. (2002). Beekeeping Association of Zimbabwe (BKAZ), Harare, The American Bee Journal Vol 14 number 11 .

Veronica, R. (2011). Sustainable Livelihoods Beekeeping in Zimbabwe "Bees Keep Trees". Green Zambezi Alliance.

Wildman, L. (2009). Beekeeping and Production of Honey. Denmark: Danish Beekeepers Association.

Zandeni, V. J. W. (1988). The Social Experience-An Introduction to Sociology. New York: Random House. 